\title{
Effects of long-term water stress on net photosynthesis, growth and water-use efficiency of conifers in the field
}

\author{
K. Gross \\ Institute of Silviculture, University of Freiburg, D-7800 Freiburg, F.R.G.
}

\section{Introduction}

Water stress strongly influences growth of trees and might also be involved in today's forest decline. There are considerable differences in susceptibility to environmental constraints in populations and between species. In the present study, a defined water stress was applied to young trees of Norway spruce and Douglas fir under otherwise natural environmental conditions. Both species were analyzed for differences in water-use efficiency and biomass production.

\section{Materials and Methods}

Sixteen 10-15 yr old and 1.5-2.5 $\mathrm{m}$ high trees (10 spruces (Picea abies) and 6 Douglas firs (Pseudotsuga menziesii) were transplanted into containers and divided into 3 groups. Four spruces originated from a single clone; the Douglas firs were not genetically uniform. One group was provided with optimal amounts of water and the other 2 received less water. The predawn water potential $\left(\psi_{\mathrm{pd}}\right)$ was used as a measure of water supply. This potential was held at a constant level in each group for a period of $2 \mathrm{yr}$ by controlling the water supply (Table I).
An NPK-fertilizer was applied to all trees in the spring.

Gas exchange was repeatedly measured in 3 fully climatized chambers (Koch systems) throughout the vegetation period on the same current year's shoots alternating between spruces and Douglas firs. The results were based on needle dry weight at the end of the vegetation period.

Water relation parameters of the youngest twigs were determined by means of the pressure-volume technique (Tyree et al., 1978; Gross and Pham-Nguyen, 1987a). Growth in height and width was measured at regular, 2 wk intervals.

After 2 yr of experimentation, the majority of the trees were felled, analyzed and dried. Dry matter of the needles, twigs, branches, trunk and large $(>10 \mathrm{~mm})$ and fine $(<10 \mathrm{~mm})$ roots were determined, with reference to their year of generation. Increase in biomass over the final vegetative period and water-use efficiency were calculated (Gross and Pham-Nguyen 1987b; Gross 1988).

Table I. Ranges of predawn leaf water potentials $\left(\psi_{\mathrm{pd}}\right)$ for the 3 treatments.

\begin{tabular}{llc}
\hline Group & Water supply & $\psi_{p d}(\mathrm{MPa})$ \\
\hline 1 & optimal & 0 to -0.3 \\
2 & limited & -0.7 to -0.8 \\
3 & very limited & -1.2 to -1.4 \\
\hline
\end{tabular}




\section{$412 s$}

\section{Results}

Trees receiving optimal water supply showed the highest net photosynthesis and thus also the fastest growth. Douglas fir was superior to spruce. Net photosynthesis in trees with limited or very limited water supply was reduced (Figs. 1, 2). The degree of reduction depended pri-

PICEA
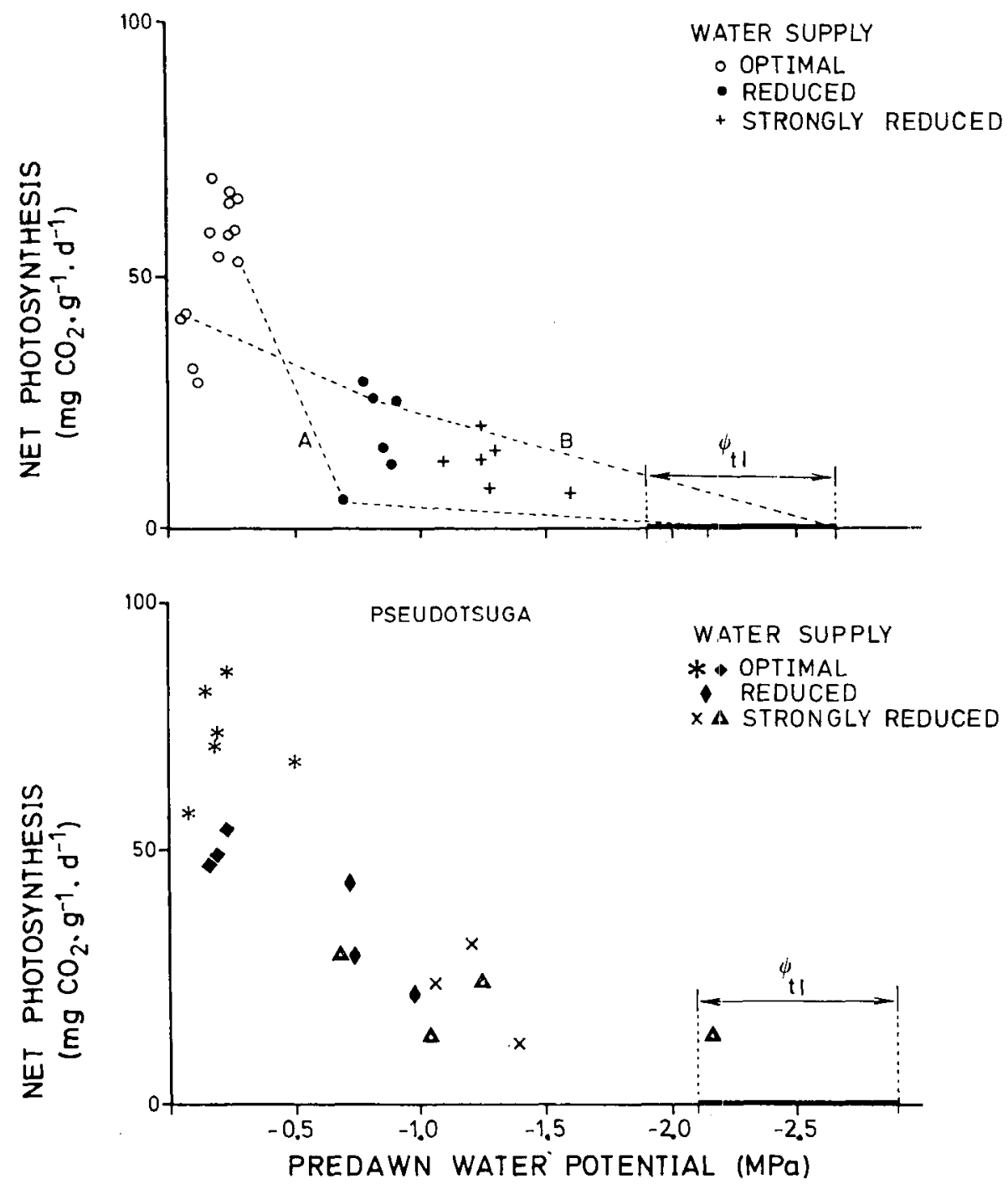

Fig. 1. Relation between daily amounts of net photosynthesis measured throughout the vegetation period and predawn water potential of current year's shoots in 1981. (Dashed line A: a hot summer day; dashed line B: an overcast autumn day, $\psi_{t}=$ (urgor loss point). 

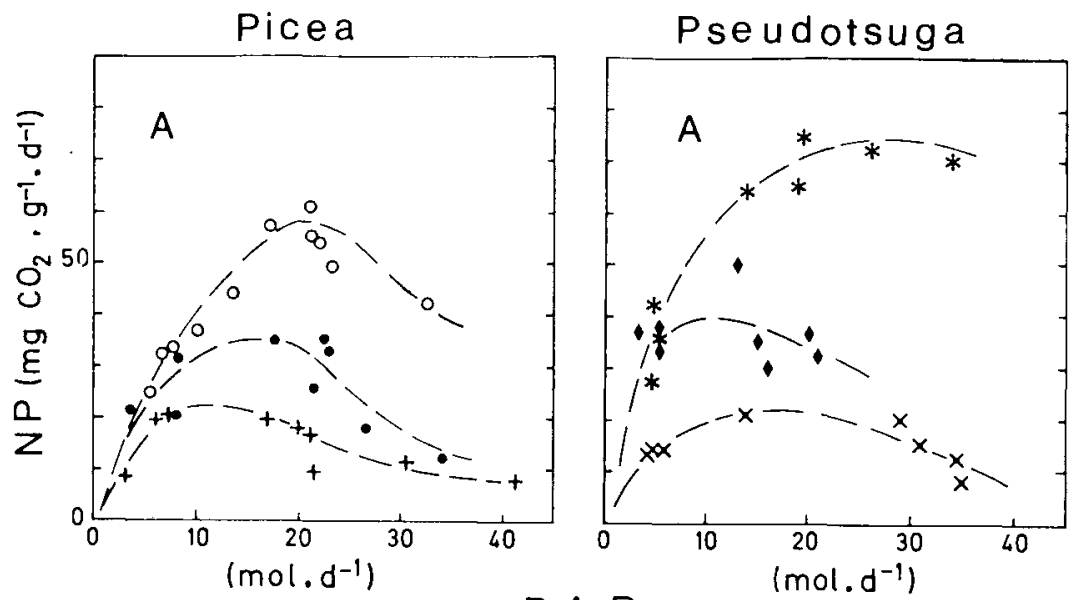

P A R
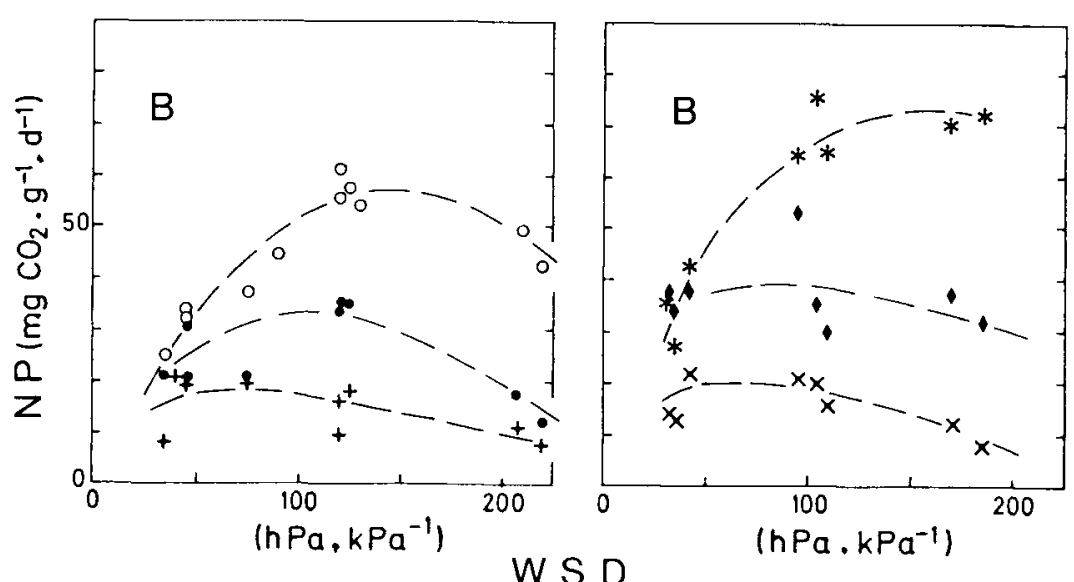

Fig. 2. A. Relation between daily amounts of net photosynthesis measured throughout the vegetation period and daily integrals of photosynthetically active radiation. B. Relation between daily amounts of net photosynthesis (the same values as in A) and daily integrals of water vapor saturation deficit (results from 1982, symbols as in Fig. 1).

marily upon intensity of water stress but was also modified by water vapor saturation deficit (WSD) and the level of the turgor loss point (Figs. 1, 2). In contrast to experiments under steady state conditions in the lab with fixed values of air humidity, daily integrals of WSD seem to be more useful under field conditions, since they take seasonal changes in daylength into consideration. Thus, the reduction in net photosynthesis was always greater on long and sunny summer days with high daily integrals of water vapor saturation deficit. On moist and overcast days or short days in autumn, however, with low daily integrals of $W S D$, the reduction in net photosynthesis was less pronounced (Figs. 1, 2). 
The turgor loss point $\left(\psi_{t 1}\right)$ sank from about -1.6 to $-2.6 \mathrm{MPa}$ in spruce and from -1.7 to $-3.0 \mathrm{MPa}$ in Douglas fir between the end of June and November (Fig. 1). Parallel to this, relative water content at loss of turgor $\left(R W C_{p}\right)$ was reduced from 85 to $74 \%$. Additional experiments have shown that net photosynthesis was reduced to zero when the predawn water potential reached the turgor loss point, reflecting complete stomatal closure. Consequently, the reduction of net photosynthesis in trees with limited and very limited water supply was more pronounced in summer than in autumn (Fig. 1).

Water-use efficiency was greater for both species under conditions of limited water supply, indicating different kinetics for $\mathrm{CO}_{2}$ and water vapor diffusion or stomatal conductance (cf. Larcher, 1960). Under conditions of good water supply, Douglas firs were more efficient than spruce trees (Figs. 3 and 4).

Long-term water stress had no effect on supply of essential nutrients to the trees.
No symptoms typical of forest decline were observed.

\section{Conclusions}

Both species cliffered in 2 essentials features reflecting adaptations to their natural habitat: 1) under conditions of good water supply, Douglas fir had a higher water-use efficiency than Norway spruce; 2) turgor loss point values for mature Douglas fir twigs were lower than those of spruce, thus indicating a better water stress tolerance. Both features probably are reasons for the high productivity of Douglas fir in central Europe.

\section{Acknowledgments}

This work was supported by Deutsche Forschungsgemeinschaft.

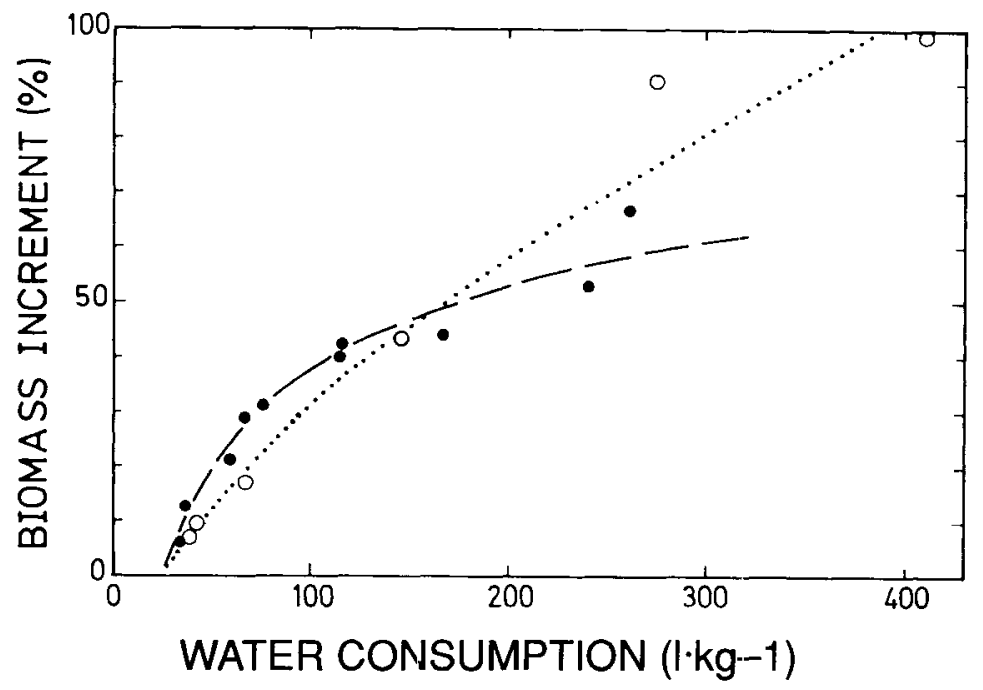

Fig. 3. Relation between yearly increment of total tree biomass (given in $\%$ of the biomass at the beginning of the last vegetation period) and yearly water consumption of sample trees related to $\mathrm{kg}$ needle dry weight. Symbols: spruce (O); Douglas fir (O). 


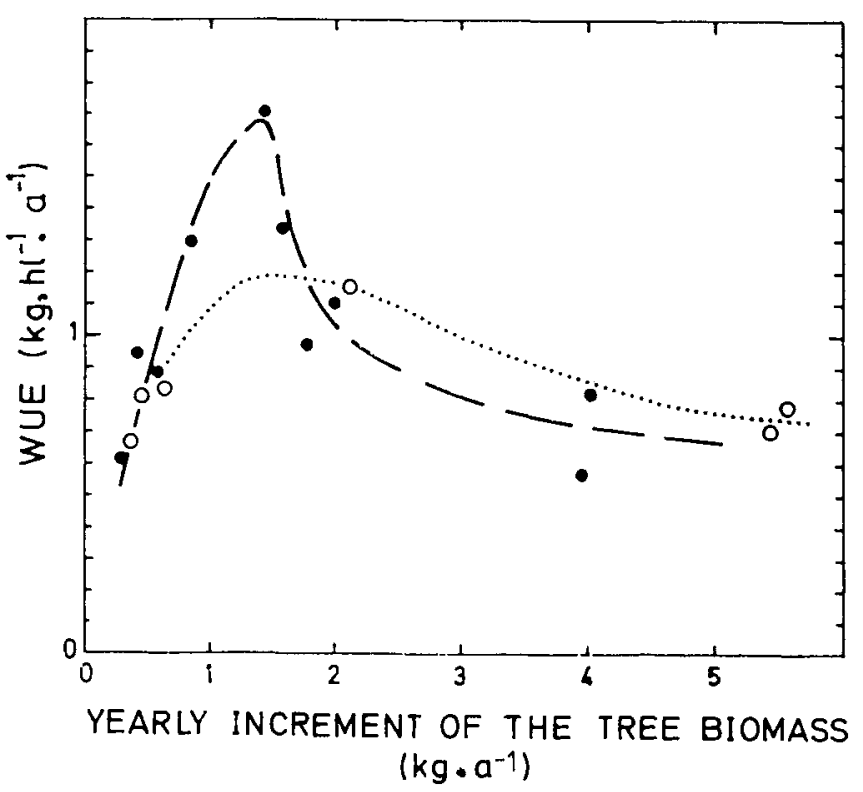

Fig. 4. Water-use efficiency (WUE) vs yearly increment of total tree biomass. Symbols: spruce (๑), Douglas fir $(O)$. The course of water-use efficiency in Douglas fir was estimated following the paltern in Fig. 3 (dotted line).

\section{References}

Gross K. (1988) Net photosynthesis, biomass production and water-use efficiency of young Norway spruces and Douglas firs, given different levels of water supply for several years in the field (in German). Allg. Forst Jagdztg. 159, 230-239

Gross K. \& Pham-Nguyen T. (1987a) Pressurevolume analyses on shoots of Picea abies and leaves of Coffea liberica at various temperatures. Physiol. Plant. 70, 189-195

Gross K. \& Pham-Nguyen T. (1987b) The influence of constant long-term water stress on net photosynthesis and growth of young spruces (Picea abies [L.] Karst) and Douglas firs (Pseudotsuga menziesii [Mirb.] Franco) in the field (in German). Forstwiss. Centralbl. 106, 7-26

Larcher W. (1960) Transpiration and photosynthesis of detached leaves and shoots of Quercus pubescens and $Q$. ilex during desiccation under standard conditions. Bull. Res. Counc. Isr. Sect. D 8, 213-224

Tyree M.T., Cheung Y.N.S., MacGregor M.E. \& Talbot A.J.B. (1978) The characteristics of seasonal and ontogenetic changes in the tissue-water relations of Acer, Populus, Tsuga, and Picea. Can. J. Bot. 56, 635-647 